\title{
Impacts of Climate Change on Seasonal Residential Electricity Consumption by 2050 and Potential Adaptation Options in Alexandria Egypt
}

\author{
Mohamed Abdel Karim A. Abdrabo, Mahmoud Adel Hassaan*, Hatem Abdelraouf \\ Institute of Graduate Studies and Research, Alexandria University, Alexandria, Egypt \\ Email: *mabdrabo@alexu.edu.eg, mhassaan@alexu.edu.eg, hatematef3003@gmail.com
}

How to cite this paper: Abdrabo, M.A.K.A., Hassaan, M.A. and Abdelraouf, H. (2018) Impacts of Climate Change on Seasonal Residential Electricity Consumption by 2050 and Potential Adaptation Options in Alexandria Egypt. American Journal of Climate Change, 7, 575-585.

https://doi.org/10.4236/ajcc.2018.74035

Received: July 9, 2018

Accepted: November 6, 2018

Published: November 9, 2018

Copyright ( 2018 by authors and Scientific Research Publishing Inc. This work is licensed under the Creative Commons Attribution International License (CC BY 4.0).

http://creativecommons.org/licenses/by/4.0/

(c) (i) Open Access

\begin{abstract}
Climate change and associated more frequent, hot or cold, extreme/weather events, as well as increasing temperature may increase future residential demand for electricity for heating and cooling purposes. The paper in hand intends to assess potential impacts of increasing temperature attributed to climate change on seasonal residential electricity consumption in Alexandria city, Egypt. Additionally, it aims to identify and discuss potential soft and hard adaptation options to such impacts. For this purpose, seasonal changes in electricity consumption were investigated. For this purpose, data on monthly residential electricity consumption, population size and income levels at district level as well as maximum monthly temperature in Alexandria city, Egypt over the period 2007-2016 were collected. This is followed by developing a panel-data model to simulate influence of temperature on residential electricity consumption. It was found that there is a significant growth trend over the study period as well as considerable seasonal variation with summer season experienced significant increase in consumption. It was found that increasing temperature, under RCP 2.6 and RCP 8.5, may contribute to significant increase in residential summer electricity consumption by 2050. Different adaptation options to such an increase in consumption, both soft and hard, have been identified and assessed.
\end{abstract}

\section{Keywords}

Climate Change, Residential Electricity Consumption, Alexandria, Modeling, Adaptation

\section{Introduction}

Demand for different energy sources is derived demand for transportation, resi- 
dential uses, industrial production...etc. Such demand depends upon a wide range of variables including economic growth, income levels, prices, land use patterns and climate parameters among other variables [1] [2]. It is suggested that major proportions of end-use energy consumption in urban areas is related to cooling or heating purposes, particularly in the residential areas that are more sensitive to temperature variations than other land uses [3]. In this respect, it was estimated that about $36 \%$ of electricity demand in USA is derived from the need for cooling and/or heating [4] [5]. The relationship between weather conditions, particularly temperature, and electricity consumption has been the subject of investigation in a large number of papers [4] [6] [7] [8] [9] [10]. Such demand for electricity for cooling purposes is usually associated with increasing differences between outdoor and indoor temperatures, and the comfortable temperature range of $19^{\circ} \mathrm{C}-22^{\circ} \mathrm{C}$ in winter and $22^{\circ} \mathrm{C}-25^{\circ} \mathrm{C}$ in summer [10]. Accordingly, the difference in the daily high and the $22^{\circ} \mathrm{C}$ is referred to as a cooling-degree day (CDD) [6].

It is projected, accordingly, that climate change and associated increase in temperature as well as extreme weather may have significant impacts on residential electricity demand [7] [8] [11]. It should be noted that, in high latitude countries, climate change is expected to lead to an increase in cooling requirements during summer and a similar decrease in heating requirements during winter implying a relatively small net impact on annual energy use [3]. However, in tropical and sub-tropical regions that experience warm winter and hot summer, the increasing needs for cooling in summer may exceed reduced needs for heating in winter leading to a relatively significant net impact on annual energy use [7].

Egypt has been experiencing, in the past years, an electricity crisis leading to frequent blackouts interrupting life and production, in which some did attribute to lack of maintenance and investment in electricity sector, heavily subsidized price, low electricity standards applied and rapid population growth.

Installed electricity generation capacities in Egypt have been experiencing between 2010/11-2014/15 an annual increase of 6.8\%, peak load, has over the same period observed an average annual increase of about $4.5 \%$ (Figure 1). Despite that installed capacities have generally been higher, during this period, than peak load, there has been shortage in electricity generation. This is because nominal installed capacity does not reflect actual capacities of such units due to their aging and lack of proper maintenance. Also, hydro power generation, in the Nile River, is highly influenced by water requirements defined by the Ministry of Water Resources and Irrigation [12].

Such a trend of increasing peak demand is expected to continue in the future, with forecasted peak demand about 54,200 MW by 2027, which is about double peak demand in 2015. It was argued that in order to meet the increase in demand, an average annual expansion in generation and transmission, $2000 \mathrm{MW}$ are needed over the next 20 years [13]. 


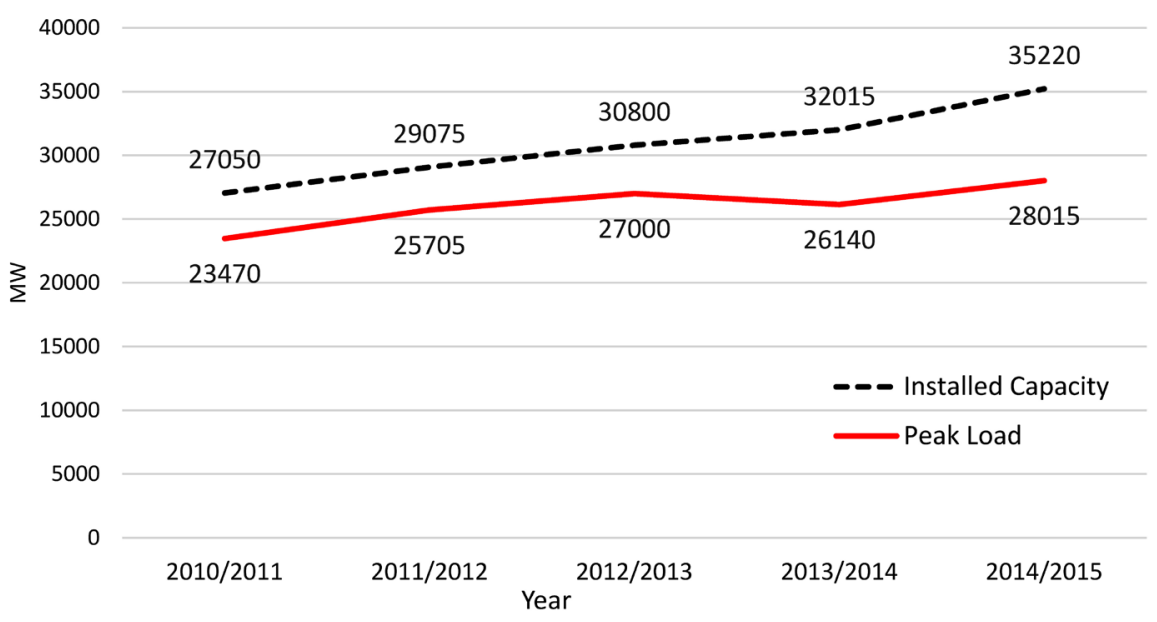

Figure 1. Development of peak load and installed capacity in Egypt during the period 2010-2015. Source: [12].

Concerning electricity consumption by sector, it was found that residential use represents, by far the largest proportion of consumption relative to other uses, with more than $50 \%$ of total usage. It was followed by industry and Government and Public utilities at about $14 \%$ and $13 \%$ of total consumption, respectively. In terms of growth, it was found that residential usage again attained the highest growth with an annual average increase of $6.7 \%$, compared to a national annual growth rate of 4.6\% between 2011/12 and 2015/16 (Figure 2). Additionally, it was found in this respect that number of subscribers to electricity provision in the residential sector has increased with an annual increase rate of 3.2\%. It was suggested that the significant growth in residential usage, compared to other users, was partially due the wide spread use of domestic appliances especially air conditioners in the summer season [12].

Such rapid growth in residential electricity consumption has led the government since 2008, to introduce block-pricing for the residential and commercial sectors, while reducing electricity subsides for different uses, with the intent of eventually eliminating energy subsidies. Additionally, recent subsidy reductions were set out as the first step in a five-year program to eliminate energy subsidies entirely. For instance, electricity tariff increased for all users, with the lowest monthly block-rate users $(0-50 \mathrm{KWh})$ receiving the sharpest increase of residential and commercial users averaging $17 \%$ [18].

In this context, climate change may become an additional stressor leading to further increases in electricity consumption due to temperature increase. The paper in hand aims to assess impacts of climate change, in terms of temperature increase, on residential electricity consumption in Alexandria, Egypt as well as potential adaptation options, in this respect.

\section{Case Study}

Alexandria city, the second largest urban center in Egypt with a total population of 5.14 million in 2017 [19], hosts the main port with about $75 \%$ of total ports 


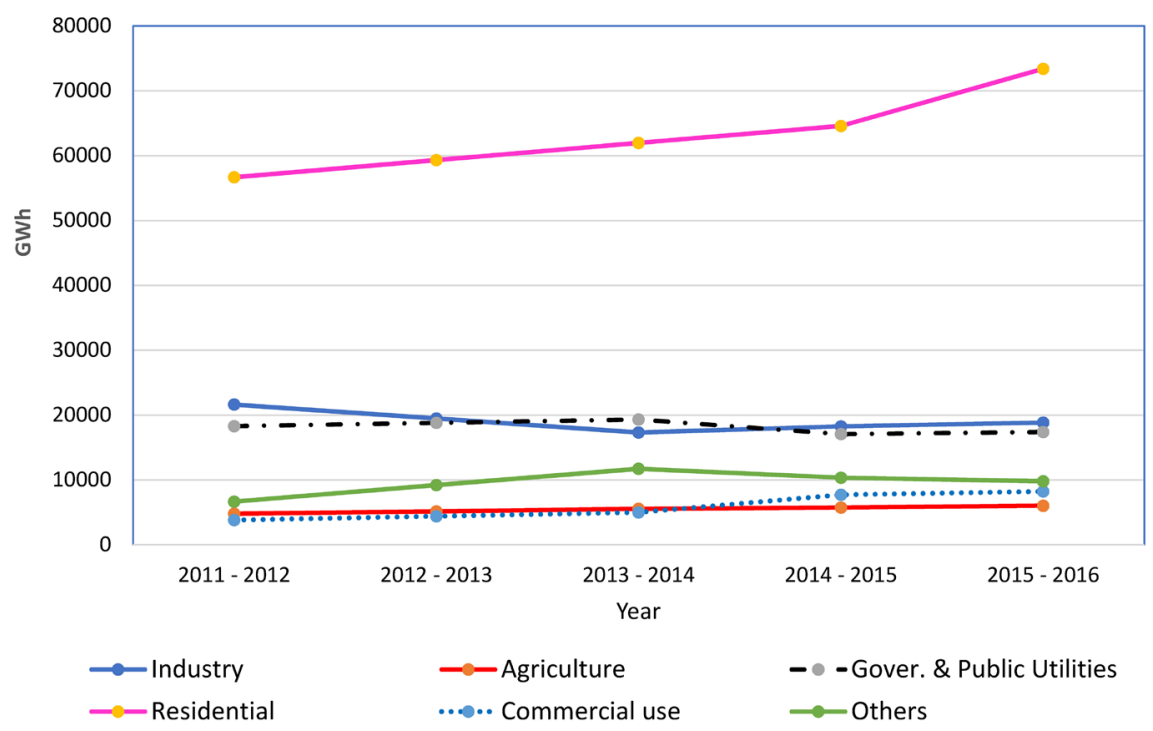

Figure 2. Electricity consumption by sector in Egypt. Source: [12] [14] [15] [16] [17].

capacity on the Mediterranean Sea. The city hosts also about 4400 industrial firms, employing around 201,000 workers and producing about 40\% of Egypt's total industrial production [20]. Alexandria city is administratively divided into 10 districts, which are further subdivided into 19 sections (Figure 3). The city, being longitudinally shaped, potentials for expansion are restricted by natural obstacles namely the Mediterranean Sea and Lake Maryut and agricultural land to the north, south and southeast, respectively (Figure 3 ). This means that locked in old districts have limited potentials for growth and the peripheral ones are experiencing most of the city growth.

Monthly residential annual electricity consumption in Alexandria has been experiencing significant growth, from 2879 to $3773 \mathrm{GWh}$, over the period 2008-2015, representing an annual average growth rate of 5.7\% [21].

Concerning electricity consumption growth trends at district level, it was found that outer districts in Alexandria have had the fastest residential electricity growth trends. This can be attributed to their higher potentials in terms of horizontal and vertical expansion and consequently hosting more population. Other inner districts, with limited potentials for expansion, have had the lowest residential electricity growth over the same period. In addition to such growth trends, residential electricity consumption showed substantial seasonal variations, with the summer season exhibiting significantly higher consumption levels compared to other seasons (Figure 4). Such seasonal variations, which are mainly associated with cooling purposes, were found to be related to prevailing socioeconomic conditions at district level, with the more affluent ones having higher seasonal variations [21].

\section{Residential Electricity Consumption: Regression Analysis}

To estimate the driving forces on seasonal electricity consumption, historical data on electricity consumption were acquired from Alexandria Electricity 


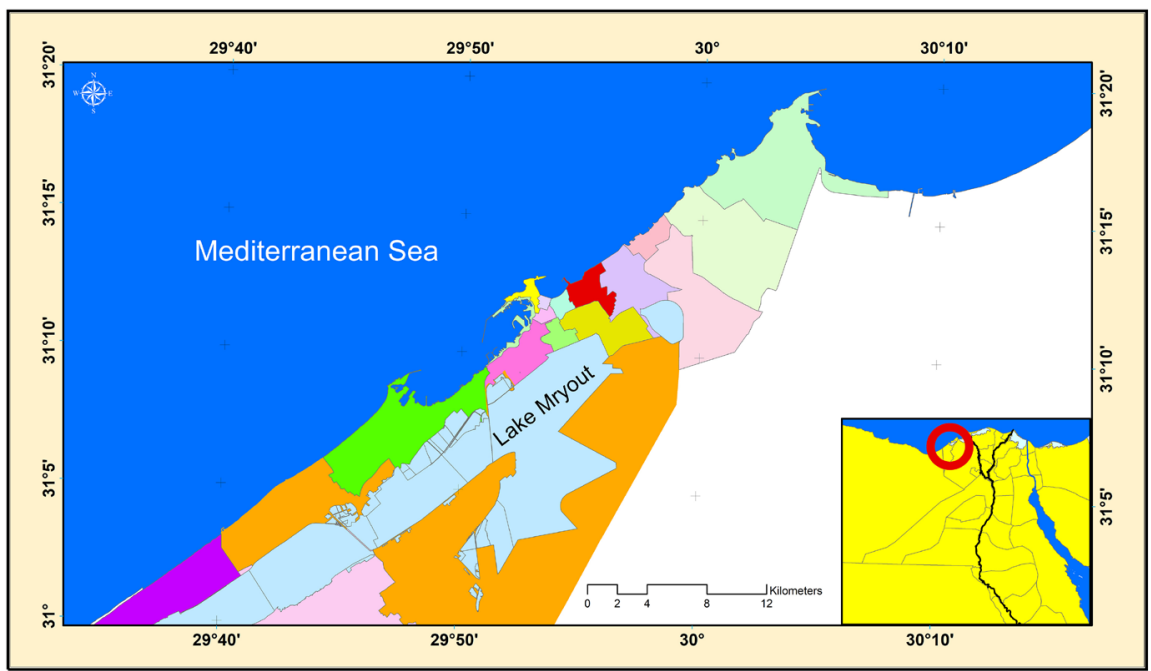

Figure 3. Administrative sections of Alexandria city.

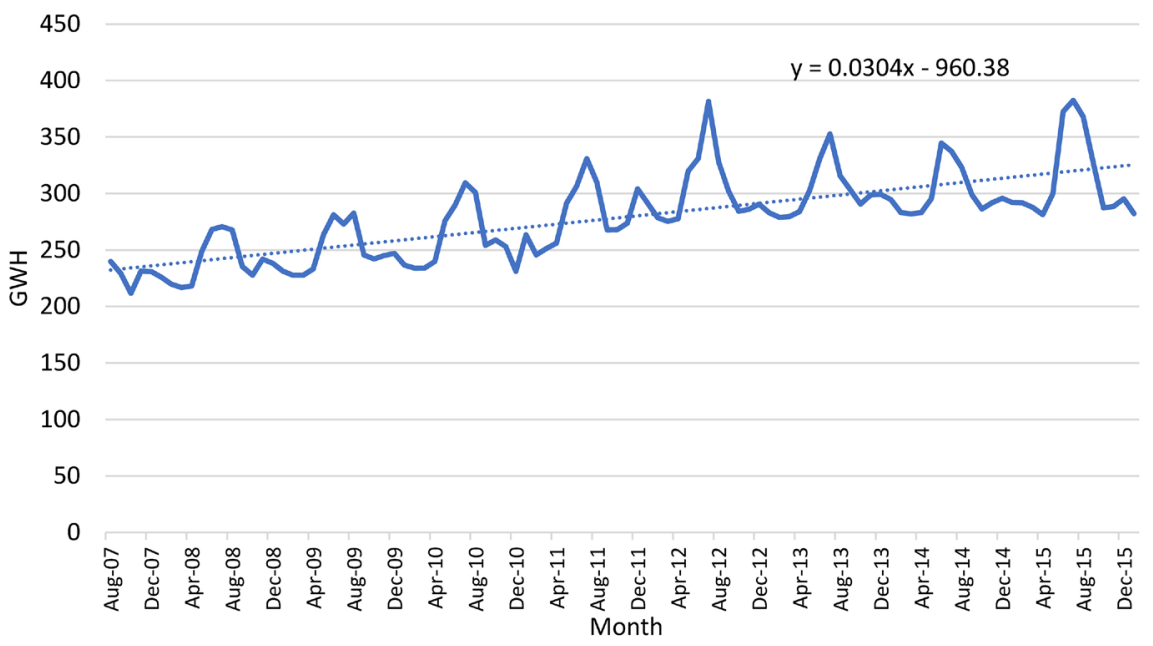

Figure 4. Monthly residential electricity consumption in Alexandria, 2007-2016 Source: [21].

Distribution Company [21], while monthly rate of temperature in Alexandria between 2007 and 2016 were acquired from Weather Underground (https://www.wunderground.com/), which is one of a commercial weather service providing real-time weather information via the Internet [22].

A Levin-Lin-Chu Unit root test [23] was conducted on the panel data to test for all individuals time series are being stationary. The test showed that all variables used in the analysis were stationary. Thereafter, a regression analysis of panel data of 9 sections in Alexandria over the period August 2007-January 2016, was undertaken for electricity consumption against max temperature, population size and GDP per capita, using fixed and random effects models (Equation (1)).

$$
\mathcal{Y}_{i t}=\beta_{\alpha}+\beta_{1} \mathcal{X}_{1 i t}+\beta_{2} \mathcal{X}_{2 i t}+\beta_{3} \mathcal{X}_{3 i t}
$$

where: 
$\mathcal{Y}_{i t}$ : residential electricity consumption for district $i$ and over time $t$,

$\mathcal{X}_{1 i t}$ : maximum monthly temperature for district $i$ and over time $t$;

$\mathcal{X}_{2 i t}$ : population size for district $i$ and over time $t$,

$\mathcal{X}_{3 i t}$ : GDP per capita for district $i$ and over time $t$

It is typically argued that marginal prices, rather than average prices should be used in demand/consumption analysis, as the latter is thought to be biased [24]. However, due to the lack of detailed household electricity consumption data marginal prices could be acquired and thus the price variable was not included in the analysis (Equation (2)).

$$
\text { Elect.con }=\propto+\beta_{1} \text { Temp }+\beta_{2} \text { Pop }+\beta_{3} \text { GDP per capita }
$$

where:

Elect.con: Monthly electricity consumption;

Temp: maximum monthly temperature;

Pop: Population size; and

GDP per capita: Gross Domestic Production Per Capita at district level.

Panel data regression was run for fixed and random effects and then a Hausman test was undertaken and based on which fixed effects were found to be the more appropriate in this case. The regression equation, according to the fixed effects was found to be:

Elect.con $=-34978.63+259.51 \mathrm{Temp}+0.08157 \mathrm{Pop}+2.2667 \mathrm{GDP}$ per capita $(3)$

It could be suggested, accordingly, that maximum temperature significantly influences residential electricity consumption mostly for cooling purposes. Based on Equation (3) above, a $1^{\circ} \mathrm{C}$ increase in maximum temperature may lead to an increase in monthly residential electricity consumption of about 259 MWh.

\section{Climate Change Impacts on Seasonal Electricity Consumption}

In order to assess impacts of climate change by 2050, in terms of maximum temperature, on residential electricity consumption, data on future maximum temperature under climate change, were downloaded from the National Center for Atmospheric Research (NCAR) NCAR's GIS Program Climate Change Scenarios GIS data portal [25]. NCAR Community Climate System Model produced climate change projections under different RCP scenarios of the (AR5) [26]. This portal provides datasets of these climate change projections in a shapefile format in $1.4 \times 1.4$ spatial resolution [25].

In order to estimate average monthly rate of expected maximum temperature by 2050 , monthly rates for the period between 2040 and 2060, according to RCP 8.5 scenario, were downloaded as point shapefiles and the average of each month during this period was calculated. Thereafter, the calculated attribute of average monthly rate was interpolated using GIS techniques to produce raster surface reflecting subtle variations of maximum temperature within the study area. 
The monthly maximum temperature in the summer season (May-September) by 2050 was found to be much higher relative to the period 2007-2016. The increase in the monthly maximum temperature is expected to reach its peak during July and August exceeding $3^{\circ} \mathrm{C}$ and $4^{\circ} \mathrm{C}$ under RCPs 2.6 and 8.5 scenarios, respectively (Figure 5). This may, in turn, have significant impacts on increasing demand for cooling purposes, which may lead to increasing residential electricity consumption.

Based upon the panel data regression analysis, presented earlier, residential electricity consumption in the 9 sections covered by the analysis would be expected to increase by $259.5 \mathrm{MWh}$ per $1^{\circ} \mathrm{C}$ maximum temperature increase (Table 1).

It is expected, in this context, that climate change would increase residential electricity consumption in Summer season by 2880 and 4118 MWh under RCP 2.6 and RCP 8.5 scenarios, respectively, by the year 2050. Such an increase represents about $0.25 \%-0.35 \%$ of 2015 summer consumption. It is worth mentioning that these estimates seem low when compared to existing state-level models relating climate parameters to residential electricity consumption indicate a nominal sensitivity of $2 \%-4 \%$ for each $1^{\circ} \mathrm{C}$ increase in ambient temperatures [27].

\section{Potential Adaptation Options}

Proper identification of potential adaptation options may require looking into other factors, in addition to those included in the analysis, which may influence electricity consumption. For instance, it was argued that urban patterns and buildings designs and orientations may influence the need for air conditioning in residential units. It was suggested that both urban patterns and building designs in Egypt may contribute to increased electricity consumption in the residential sector [28] [29]. Furthermore, recent development in different parts of

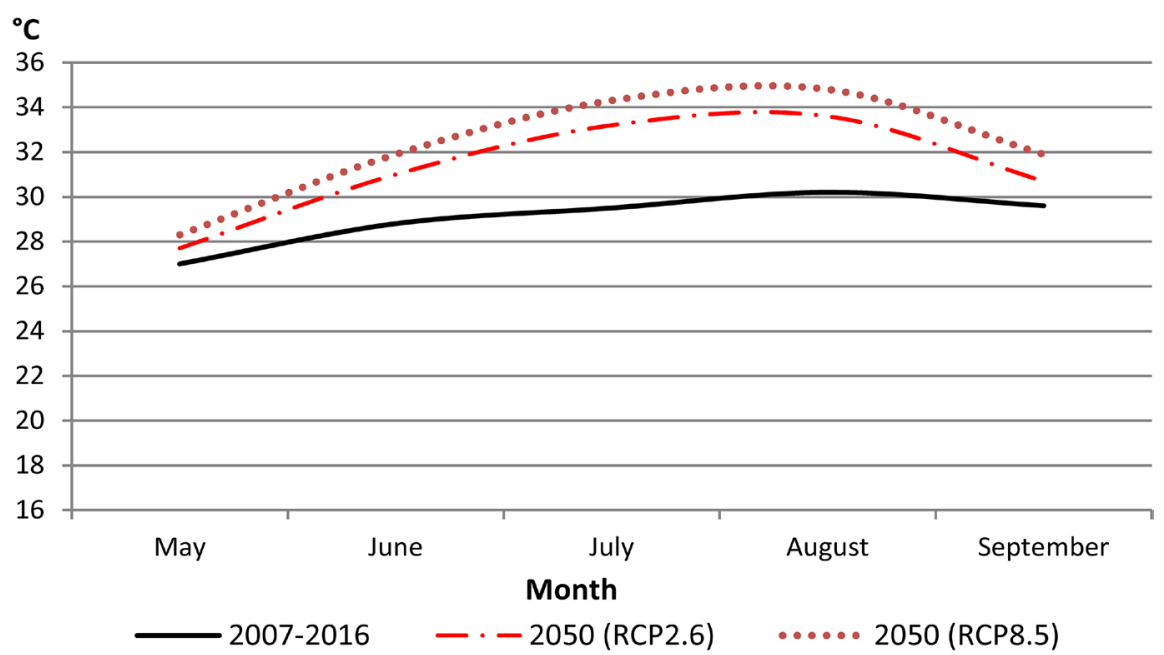

Figure 5. Current and expected Monthly maximum temperature in Alexandria. Source: [22] [25]. 
Table 1. Impacts of increasing maximum temperature under climate change scenarios on residential electricity consumption in the nine section.

\begin{tabular}{ccc}
\hline \multirow{2}{*}{ Month } & \multicolumn{2}{c}{ Electricity consumption change MWh } \\
\cline { 2 - 3 } & $2050($ RCP 2.6) & $2050($ RCP 8.5) \\
May & 182 & 337 \\
June & 571 & 804 \\
July & 960 & 1246 \\
August & 882 & 1194 \\
September & 285 & 597 \\
Total & 2880 & 4178 \\
\hline
\end{tabular}

Alexandria city, which is mostly undertaken haphazardly, involved replacing old buildings by new high-rise 15 - 20 floors buildings blocks exceeding the limits identified by the building code, in quite narrow 6 - 7 meters streets (Figure 6).

Possible adaptation options to increasing electricity consumption for cooling purposes would involve hard options and soft options; with the former involving actions such as investing in additional electricity generation and transmission network capacities. This would, nevertheless, involve massive spending to meet both initial capital investment as well as operational cost. For instance, Assuming that there would be a need to increase electricity generation capacity through constructing a new natural gas power plant of a capacity of $640 \mathrm{MW}$, the total cost of such a plant would involve overnight capital cost in addition to operation and maintenance cost [30].

The construction cost of such a plant was estimated based on the recently signed contract between the Ministry of Electricity and Renewable Energy in Egypt and Siemens, which involved US $\$ 6.5$ billion to generate 14,400 MW. This means an average overnight cost of about 450,000 US\$/MW and an overnight capital cost of US\$ 279 million for the needed power plant. According to the International Energy Agency (2015) capital investment in a gas-fired power plant represents, at a $10 \%$ discount rate, about $20 \%$ of total levelized cost, meaning total levelized cost for the plant being considered would be around US\$ million 1390 including capital investment, operation and maintenance cost and fuel cost for the life span of the plant. It should be noted, meanwhile, that this figure does not include capital borrowing cost, decommissioning cost and any additional burden to fluctuation in exchange rates.

Alternatively, other soft adaptation measures may include the application of economic instruments (e.g. more strict pricing mechanisms) or the introduction of more stringent electricity efficiency standards for cooling purposes appliances and enforcing urban planning codes that may improve internal and housing environments and thus reducing the need for cooling purposes.

It is worth mentioning that, despite that each group of adaptation measures has their pros and cons, hard options typically involve significant investments 


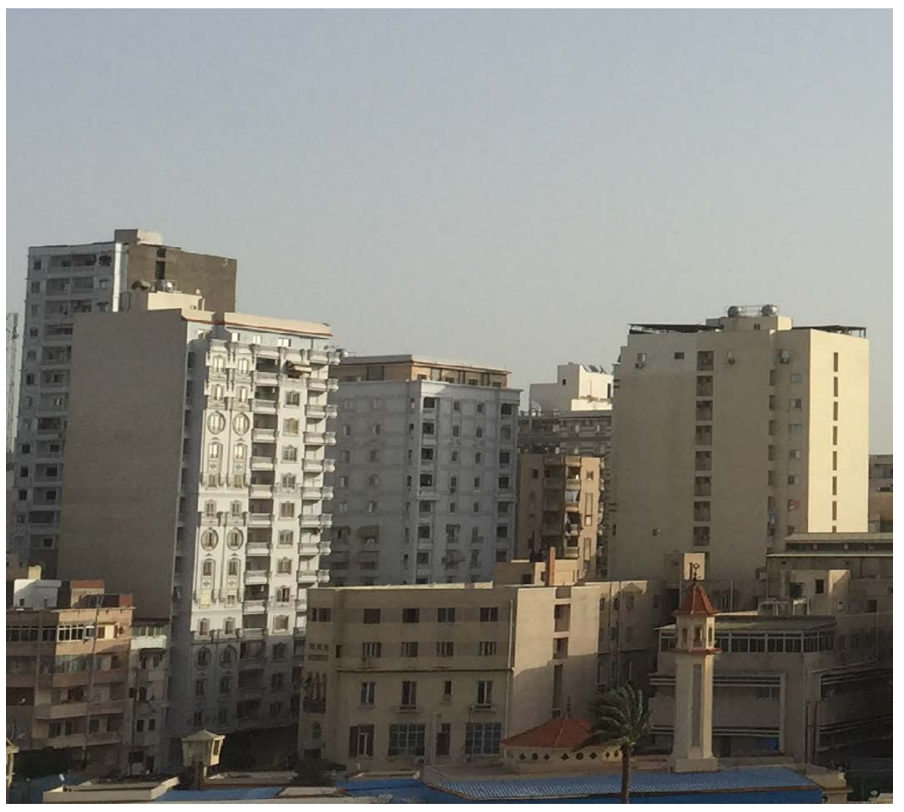

Figure 6. Dense high rising blocks in Alexandria.

that would involve high opportunity cost, particularly in a developing country like Egypt.

\section{Conclusions}

Changing electricity consumption is generally associated, along with other socioeconomic variables, with weather conditions, particularly temperature. It is expected that climate change may contribute to further increases in electricity consumption for cooling purposes during summer.

Conducted regression analysis revealed that current electricity consumption in residential sector in Alexandria is significantly influenced by maximum monthly temperature, along with population size and GDP per capita. Accordingly, it was found that electricity consumption may be expected to increase under different climate change scenarios in Alexandria city by 2050. The increase in electricity consumption in summer season due to climate change was estimated to be about 2880 and 4118 MWh under RCP 2.6 and RCP 8.5 scenarios, respectively, by 2050 . Such figures may be underestimates as electricity consumption for cooling purposes under climate change is expected to be exacerbated by unplanned and ill-advised urban structures development patterns and internal design, which reduce air circulation and alter local climate leading to human discomfort and increasing need to cooling.

To cope with such increasing electricity consumption due to climate change, a number of adaptation options were identified including upgrading capacities of electricity generation units and electricity networks. Also, they may involve applying economic instruments such as pricing and taxes and/or urban planning to adapt to the increase in electricity consumption due to climate change. However, successful implementation of any of such options may require more in-depth 
assessment in terms of their impacts on market behavior as well as their socioeconomic and environmental consequences.

\section{Acknowledgements}

This research work is part of a research project sponsored by the IDRC-Canada for establishing Alexandria Research Center for Adaptation to Climate Change (ARCA) at Alexandria University, Egypt.

\section{Conflicts of Interest}

The authors declare no conflicts of interest regarding the publication of this paper.

\section{References}

[1] Chen, S.-T., Kuo, H.-I. and Chen, C.-C. (2007) The Relationship between GDP and Electricity Consumption in 10 Asian Countries. Energy Policy, 35, 2611-2621. https://doi.org/10.1016/j.enpol.2006.10.001

[2] RCREEE, R.C.f.R.E.a.E.E., (2017) Arab Future Energy Index ${ }^{\text {Tm }}$ (AFEX) 2017 Energy Efficiency. Amman.

[3] Crowley, C. and Joutz, F.L. (2005) Final Report EPA Weather Effects on Electricity Loads. USEPA, 1-48.

[4] Hashimoto, Y., Ihara, T., Ohashi, Y., Nabeshima, M., Shigeta, Y. and Kikegawa, Y. (2015) Sensitivity of Electricity Consumption to Air Temperature, Air Humidity and Solar Radiation in City-Block Scale Based on 2013 Osaka City Observation. 9 th International Conference on Urban Climate Jointly with 12 th Symposium on the Urban Environment, Toulouse, 20-24 July 2015, 5.

[5] Williams, L., Smith, J. and Mendelsohn, R. (2003) Global Climate Change and California: Potential Implications for Ecosystems, Health, and the Economy. California Energy Commission, Public Interest Energy Research Program, California.

[6] Hor, C.L., Watson, S.J. and Majithia, S. (2005) Analyzing the Impact of Weather Variables on Monthly Electricity Demand. IEEE Transactions on Power Systems, 20, 2078-2085. https://doi.org/10.1109/TPWRS.2005.857397

[7] Pilli-Sihvola, K., et al. (2010) Climate Change and Electricity ConsumptionWitnessing Increasing or Decreasing Use and Costs? Energy Policy, 38, 2409-2419. https://doi.org/10.1016/j.enpol.2009.12.033

[8] Auffhammer, M. and Mansur, E.T. (2014) Measuring Climatic Impacts on Energy Consumption: A Review of the Empirical Literature. Energy Economics, 46, 522-530. https://doi.org/10.1016/j.eneco.2014.04.017

[9] Hernández, L., et al. (2012) A Study of the Relationship between Weather Variables and Electric Power Demand inside a Smart Grid/Smart World Framework. Sensors, 12, 11571-11591. https://doi.org/10.3390/s120911571

[10] Jakušenoks, A. and Laizāns, A. (2016) Weather Impact on the Household Electric Energy Consumption. Research for Rural Development, 1, 248-253.

[11] Limones-Rodríguez, N., et al. (2017) The Impact of Climate Change on Air Conditioning Requirements in Andalusia at a Detailed Scale. Theoretical and Applied Climatology, 134, 1047-1063.

[12] EEHC (2017) Annual Report 2015-2016. Egyptian Electricity Holding Company, Cairo. 
[13] Osman, S.H. (not dated) Overview of the Electricity Sector in Egypt. http://www.medreg-regulators.org/Portals/45/capacitybuilding/2nd/2nd_Capacity_ Building_Session1_EGYPTERA.pdf

[14] EEHC (2013) Annual Report 2011-2012. Egyptian Electricity Holding Company, Cairo.

[15] EEHC (2014) Annual Report 2012-2013. Egyptian Electricity Holding Company, Cairo.

[16] EEHC (2015) Annual Report 2013-2014. Egyptian Electricity Holding Company, Cairo.

[17] EEHC (2016) Annual Report 2014-2015. Egyptian Electricity Holding Company, Cairo.

[18] James, L.M. (2015) Recent Developments in Egypt's Fuel Subsidy Reform. International Institute for Sustainable Development, Geneva.

[19] CAPMAS (2017) Population Census 2017. Central Agency for Public Mobilization and Statistics, Cairo.

[20] Haskoning, R. (2007) Alexandria Development Project Integrated Environmental and Social Impact Assessment. Alexandria Governorate, Alexandria.

[21] AEDC (2016) Electricity Consumption in Alexandria: 2007-2016, Residential Sector. Alexandria Electricity Distribution Company.

[22] Wu, W.U. (2016) Weather Underground. https://www.wunderground.com/

[23] Levin, A., Lin, C. and Chu, C. (2002) Unit Root Tests in Panel Data: Asymptotic and Finite-Sample Properties. Journal of Econometrics, 108, 1-24. https://doi.org/10.1016/S0304-4076(01)00098-7

[24] Nauges, C.a.B. (2002) Estimating Residential Water Demand under Block Rate Pricing: A Nonparametric Approach. Working Paper, Unité Mixte de Recherche de l'Institut National de la Recherche Agronomique (INRA), Et de l'Université des Sciences Sociales de Toulouse, Toulouse, 18.

[25] NCAR (2014) GIS Data Services Are Provided by NCAR GIS Program through Climate Change Scenarios Version 2.0, 2012. http://www.gisclimatechange.org

[26] IPCC (2013) Summary for Policymakers. In: Climate Change 2013: The Physical Science Basis, Contribution of Working Group I to the Fifth Assessment Report of the Intergovernmental Panel on Climate Change 2013, Cambridge University Press, Cambridge, 29.

[27] Sailor, D.J. and Pavlova, A.A. (2003) Air Conditioning Market Saturation and Long-Term Response of Residential Cooling Energy Demand to Climate Change. Energy, 28, 941-951. https://doi.org/10.1016/S0360-5442(03)00033-1

[28] Attia, S.G., Evrard, A. and Gratia, E. (2011) Development of Benchmark Models for the Egyptian Residential Buildings Sector. Applied Energy, 94, 270-284. https://doi.org/10.1016/j.apenergy.2012.01.065

[29] Ahmed, A.N., et al. (2011) Using Simulation Tools. Proceedings of Building Simulation 2011: 12th Conference of International Building Performance Simulation Association, Sydney, 14-16 November 2011, 1141-1148.

[30] IEA, NEA and OECD (2015) Projected Costs of Generating Electricity-Edition. OECD, Paris. 